\title{
GMR
}

\section{Detection of a mutation at codon 43 of the rpsL gene in Xanthomonas oryzae pv. oryzicola and $X$. oryzae pv. oryzae by PCR-RFLP}

\author{
Y. Zhang ${ }^{1,2 *}$, X. Yang ${ }^{1 *}$, F.Y. Zhou ${ }^{1}$, A.F. Zhang ${ }^{1}$, X.F. Zhu' ${ }^{2}$, Y. Chen ${ }^{1,2}$, M.G. Zhou ${ }^{2}$ \\ and T.C. Gao' \\ ${ }^{1}$ Institute of Plant Protection and Agro-products Safety, \\ Anhui Academy of Agricultural Sciences, Hefei, China \\ ${ }^{2}$ College of Crop Protection, Nanjing Agricultural University, Nanjing, China \\ *These authors contributed equally to this study. \\ Corresponding author: T.C. Gao \\ E-mail: gtczbs@sina.com \\ Genet. Mol. Res. 14 (4): 18587-18595 (2015) \\ Received August 10, 2015 \\ Accepted October 18, 2015 \\ Published December 28, 2015 \\ DOI http://dx.doi.org/10.4238/2015.December.28.6
}

\begin{abstract}
The aim of this study was to develop a method to detect a point mutation in the ribosomal S12 protein ( $r p s \mathrm{~L}$ ) gene in streptomycinresistant strains of Xanthomonas oryzae pv. oryzicola and $X$. oryzae pv. oryzae. The polymerase chain reaction-restriction fragment length polymorphism (PCR-RFLP) method was developed to detect a point mutation in codon 43 of the rpsL gene in $X$. oryzae pv. oryzicola and $X$. oryzae pv. oryzae. The 304-bp PCR product from the rpsL gene was digested by Mboll to form two fragments (201 and $103 \mathrm{bp}$ ) if there was a mutation at codon 43 , or three fragments $(146,103$, and $55 \mathrm{bp})$ if there was no mutation. Compared with the results from nucleotide sequencing, the PCR-RFLP method was accurate in detecting the point mutation at codon 43 of the rps $L$ gene in streptomycin-resistant strains of $X$. oryzae pv. oryzicola and $X$. oryzae pv. oryzae. These results indicate that the
\end{abstract}


PCR-RFLP is a simple, rapid and reliable method for detecting the point mutation at codon 43 of the rpsL gene.

Key words: Molecular diagnosis of PCR-RFLP; Point mutation; Ribosomal protein $\mathrm{S} 12$ (rpsL) gene; $X$. oryzae pv. oryzae; Xanthomonas oryzae pv. oryzicola

\section{INTRODUCTION}

Bacterial blight, caused by Xanthomonas oryzae pv. oryzae, and bacterial leaf streak, caused by $X$. oryzae $p v$. oryzicola, are two of the most serious bacterial diseases of rice in many rice-growing regions of the world, including southern China (Strange et al., 2005; Jeung et al., 2006; Nino-Liu et al., 2006; Kang et al., 2008). Each of these diseases can cause a loss of at least $10 \%$ yield in susceptible rice varieties under appropriate climatic conditions (Chen et al., 2004; Lai et al., 2004; Kang et al., 2008; Salzberg et al., 2008).

The antibiotic streptomycin was discovered in the 1950s (Sundin et al., 1993) and was first used to control bacterial diseases in humans and then in agriculture to control bacterial diseases in crops such as rice (Yong et al., 2004). Streptomycin has also been used in China to control citrus bacterial canker disease (caused by $X$. campestris pv. citri), bacterial soft rot of Chinese cabbage (caused by Enwinia carotovora subsp carotovora), tobacco wildfire (caused by Pseudomonas syringae pv. tabaci), and bacterial blight and bacterial leaf streak of rice. Chromosomally acquired resistance to streptomycin is often due to mutations or other molecular changes in the genes encoding ribosomal protein S12 (rpsL) and 16S rRNA (rrs) (Wu et al., 2006). The strA-strB genes (Sundin et al., 2000, 2002) and aadA gene (Li et al., 2004; Poole et al., 2004; Weldhagen et al., 2004) are also involved in streptomycin resistance. In our previous research, laboratory-induced streptomycin resistance in $X$. oryzae pv. oryzicola and $X$. oryzae pv. oryzae was found following the mutation of Lys (AAG) to $\operatorname{Arg}(A G G)$ at the 43rd or 88th amino acid residue in rpsL.

Polymerase chain reaction-restriction fragment length polymorphism (PCR-RFLP) relies on the production of considerable amounts of amplicons of a known nucleic acid sequence by PCR and subsequent restriction-enzyme digestion of the amplified DNA products. The generated fragments are separated by gel electrophoresis according to their sizes. Restriction enzymes (DNAdependent endonucleases) recognize specific short palindromic sequences of 4-8 nucleotides. They hydrolyze (cleave) the phosphodiester backbone of both DNA strands at these specific recognition sites (Al Dahouk et al., 2005).

In this study, we analyzed the rpsL gene from mutant (streptomycin-resistant) and wildtype strains of $X$. oryzae pv. oryzicola and $X$. oryzae pv. oryzae, and developed a specific molecular test for mutations at codon 43 in rpsL.

\section{MATERIAL AND METHODS}

\section{Strains}

The 23 strains used in this study are listed in Table 1. These strains included the streptomycin-sensitive strains RS105 and PXO99, and the streptomycin-resistant mutants from W-YNB9-1, SCB4-3, ZJ173, and PXO99. All strains were maintained on nutrient agar (NA) at $28^{\circ} \mathrm{C}$. 
NA contained $5 \mathrm{~g}$ polypeptone, $1 \mathrm{~g}$ yeast powder, $3 \mathrm{~g}$ beef extract, $15 \mathrm{~g}$ sucrose, and $17 \mathrm{~g}$ agar per liter. The $\mathrm{pH}$ was adjusted to 7.0 with $10 \mathrm{M}$ sodium hydroxide. Nutrient broth (NB) medium was the NA medium without agar.

\section{DNA isolation}

DNA isolation was performed as described by Yong et al. (2011). After the bacterial suspension was cultured at $28^{\circ} \mathrm{C}$ overnight, $1.5 \mathrm{~mL}$ of the suspension was centrifuged at $12,000 \mathrm{~g}$ for $10 \mathrm{~min}$. The pellet was resuspended in $567 \mu \mathrm{L}$ TE buffer (10 mM Tris- $\mathrm{HCl}, 1 \mathrm{mM}$ EDTA, pH 8.0). Proteinase $\mathrm{K}$ and sodium dodecyl sulfate (SDS) were added at final concentrations of $100 \mu \mathrm{g} / \mathrm{mL}$ and $5 \mathrm{~g} / \mathrm{L}$, respectively. After incubation for $1 \mathrm{~h}$ at $37^{\circ} \mathrm{C}$, sodium chloride and hexadecyltrimethylammonium bromide (CTAB) were added to each preparation at final concentrations of $0.7 \mathrm{M}$ and $10 \mathrm{~g} / \mathrm{L}$, respectively. The preparations were incubated at $65^{\circ} \mathrm{C}$ for $10 \mathrm{~min}$, and DNA was extracted with chloroform + isoamylalcohol $(24+1$ by volume). Samples were shaken for 10 min and centrifuged at $12,000 \mathrm{~g}$ for $20 \mathrm{~min}$. DNA was re-extracted with phenol + chloroform + isoamylalcohol $(25+$ $24+1$ by volume) and centrifuged as described. DNA was precipitated by adding $0.6 \mathrm{X}$ volume of isopropanol and incubating at $-20^{\circ} \mathrm{C}$ for $30 \mathrm{~min}$. Samples were centrifuged at $12,000 \mathrm{~g}$ for $20 \mathrm{~min}$, and the pellets were washed with $1 \mathrm{~mL} 70 \%$ ethanol and centrifuged. The DNA was dried at room temperature, and the pellet was then dissolved in sterilized ultrapure water $(50 \mu \mathrm{L})$ and stored at $-20^{\circ} \mathrm{C}$.

\section{PCR amplification}

A pair of oligonucleotide primers was designed (rpsLnF-5'-ATCAACTGATGACGACGATCA ATCA-3' and rpsLnR-5'-CGGACGGTGTGATAACGCACAC-3') to amplify a 304-bp fragment of $r p s L$ from the genomic DNA of mutants of $X$. oryzae pv. oryzicola strain BLS256. PCR was performed in a total reaction volume of $25 \mu \mathrm{L}$ on an automatic thermal controller. The reaction mixture contained 2.5 $\mu \mathrm{L}$ 10X buffer, $2 \mu \mathrm{L}$ dNTPs, $1.5 \mu \mathrm{L} \mathrm{MgCl}_{2}, 20$ pmol each primer, and $2.5 \mathrm{U}$ Taq polymerase. The PCR procedure was as follows: pre-denaturation at $94^{\circ} \mathrm{C}$ for $5 \mathrm{~min}$; followed by 30 cycles of $94^{\circ} \mathrm{C}$ for $40 \mathrm{~s}$, $63^{\circ} \mathrm{C}$ for $100 \mathrm{~s}$, and $72^{\circ} \mathrm{C}$ for $60 \mathrm{~s}$; and a final extension at $72^{\circ} \mathrm{C}$ for $10 \mathrm{~min}$. Amplified DNA fragments were detected by electrophoresis on $1.5 \%$ agarose gels.

PCR products were purified and sequenced by Liangzhong Bioengineering Company, Ltd. (Shanghai, China). Primers were synthesized by Shanghai Bioengineering Company (Shanghai, China).

\section{PCR-RFLP}

For rapid detection of the mutation at codon 43 of $r p s L$, the PCR products were cleaved by the restriction enzyme Mboll. The reaction mixture contained $5 \mu \mathrm{L} \mathrm{PCR}$ product, $1 \mu \mathrm{L}$ Mboll (10 $\mathrm{U} / \mu \mathrm{L}), 1 \mu \mathrm{L}$ reaction buffer (10 $\mathrm{mM}$ Tris- $\mathrm{HCl}, 10 \mathrm{mM} \mathrm{MgCl}_{2}$, and $1 \mathrm{mM}$ dithiothreitol, $\mathrm{pH} 7.5$ ), and $3 \mu \mathrm{L}$ deionized distilled water. The reaction was carried out at $37^{\circ} \mathrm{C}$ for $3 \mathrm{~h}$, and the products were detected by electrophoresis on $2 \%$ agarose gels.

\section{DNA sequencing}

A pair of oligonucleotide primers was designed (5'-CGGACGAGGAGTAAGCG-3' and 5'-AT GAAGC G GGCAATGGT-3') to amplify the whole rpsL sequence from BLS256. PCR products from 
all 23 strains were purified and sequenced by Liangzhong Bioengineering Company, Ltd. (Shanghai, China). Primers were synthesized by Shanghai Bioengineering Company (Shanghai, China).

\section{RESULTS}

\section{RFLP analysis}

PCR with primers specific for $r p s L n F$ and $r p s L n R$ generated a fragment that was $304 \mathrm{bp}$ from RS105, PXO99 and its mutants (Figure 1). The rpsL codon 43 in wild-type strains of $X$. oryzae pv. oryzicola and $X$. oryzae pv. oryzae contained a Mboll restriction enzyme site. The mutation at codon 43 of $r p s L$ in streptomycin-resistant strains results in the loss of the Mboll site at that codon.

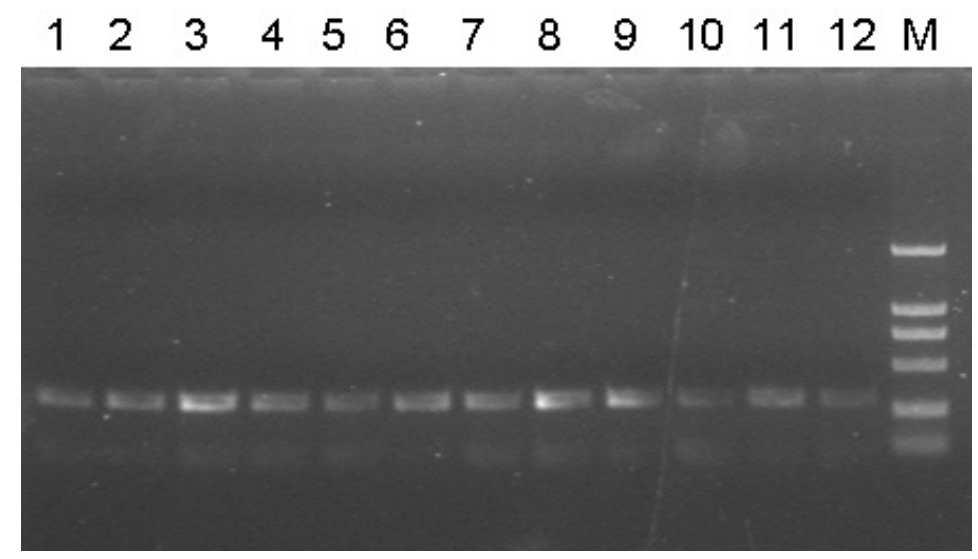

Figure 1. PCR fragments of $r p s L$ from RS105, PXO99 and its mutants amplified using the primers $r p s L n F$ and $r p s L n R$. Lanes 1-6 = UV-w-1, UV-w-2, UV-w-3, YJ-w-1, YJ-w-2, and RS105. Lanes 7-12 = UV-z-1, YJ-z-1, UV-p-1, UV-p-2, YJp-1, and PXO99; lane $M=$ DL2000.

The results of RFLP analyses of the rpsL genes are shown in Figure 2. Two RFLP patterns were observed. In pattern A, the 304-bp product was digested by Mboll, which generated two fragments (201 and $103 \mathrm{bp}$ ), indicating the presence of a mutation at codon 43 . In pattern $B$, the 304-bp product was digested into three fragments (146, 103, and $55 \mathrm{bp})$, indicating the absence of a mutation at codon 43 . The 55 -bp fragment (the middle fragment) was so short that it often moved completely through the $2 \%$ agarose gels before the gels were stained (Figures 2 and 3 ).

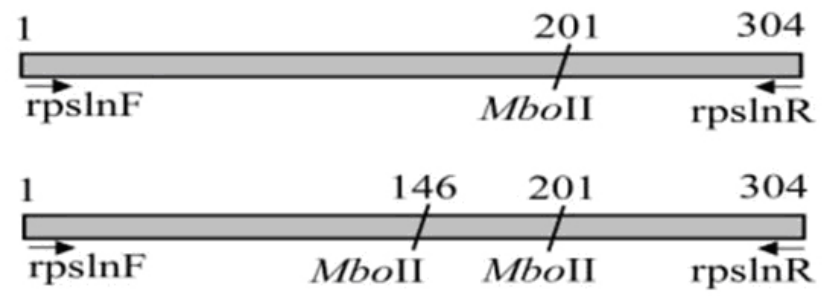

$\mathrm{C}$

$\mathrm{D}$

Figure 2. Genomic DNA amplified by the primers $r p s L n F$ and $r p s L n R$ and cleaved by Mboll. Arrowheads indicate the locations of the primers used for PCR. Mboll restriction sites are indicated. C, the mutation at codon 43; D, the mutation at codon 88 or no mutation (wild-type strain). 


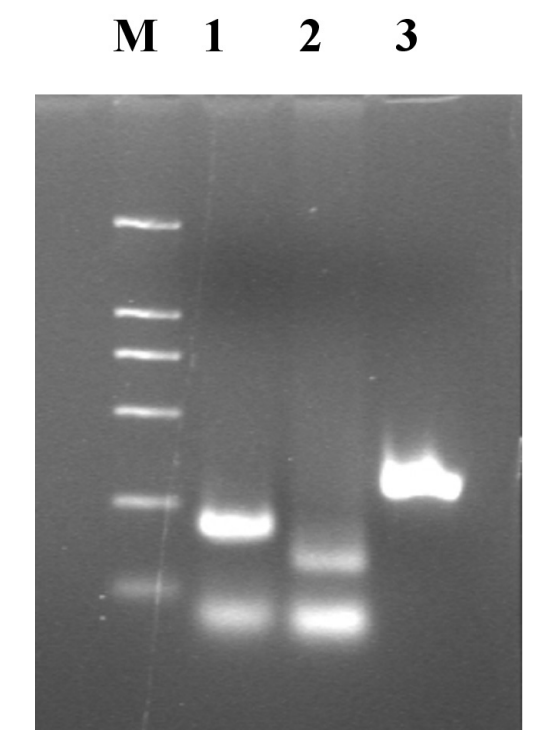

Figure 3. Mboll restriction patterns of the PCR-amplified $r p s L$ gene. Lane $1=P C R$ product digested with Mboll (pattern A in Table 1). Lane $2=$ digested PCR product with Mboll (pattern B in Table 1). Lane $3=$ undigested PCR product; lane $M=\mathrm{DL} 2000$.

Of the 11 streptomycin-resistant strains of $X$. oryzae pv. oryzicola, four produced pattern $A$ and seven produced pattern $B$ (Figure 4 and Table 1). Of the 10 streptomycin-resistant strains of $X$. oryzae pv. oryzae, four produced pattern A and six produced pattern B (Figure 5 and Table 1). Streptomycin-sensitive strains RS105 and PXO99 produced pattern B (Figures 4, 5, and Table 1).

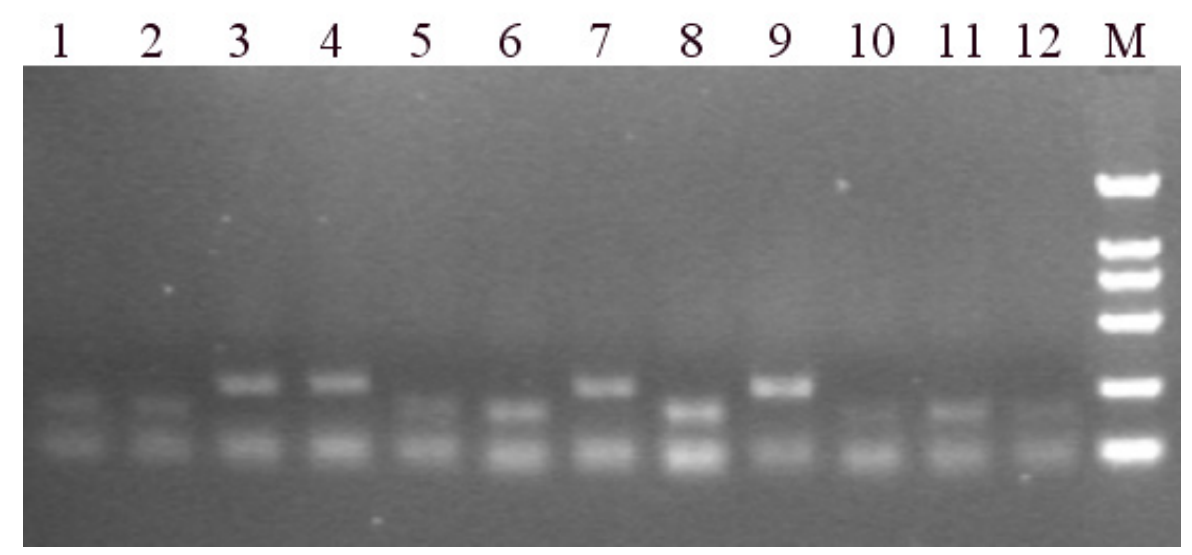

Figure 4. Detection of mutations at codon 43 of the $r p s L$ gene in $X$. oryzae pv. oryzicola by RFLP analysis. Two patterns of digestion of the 304-bp amplified fragment of the rpsL gene by Mboll are shown. Lanes 1-12 = UV-W1, UV-w-2, UV-w-3, YJ-w-1, YJ-w-2, YJ-w-3, YJ-w-4, UV-S-1, UV-S-2, YJ-S-1, YJ-S-2, and RS105, respectively; lane $M=\mathrm{DL} 2000$. 


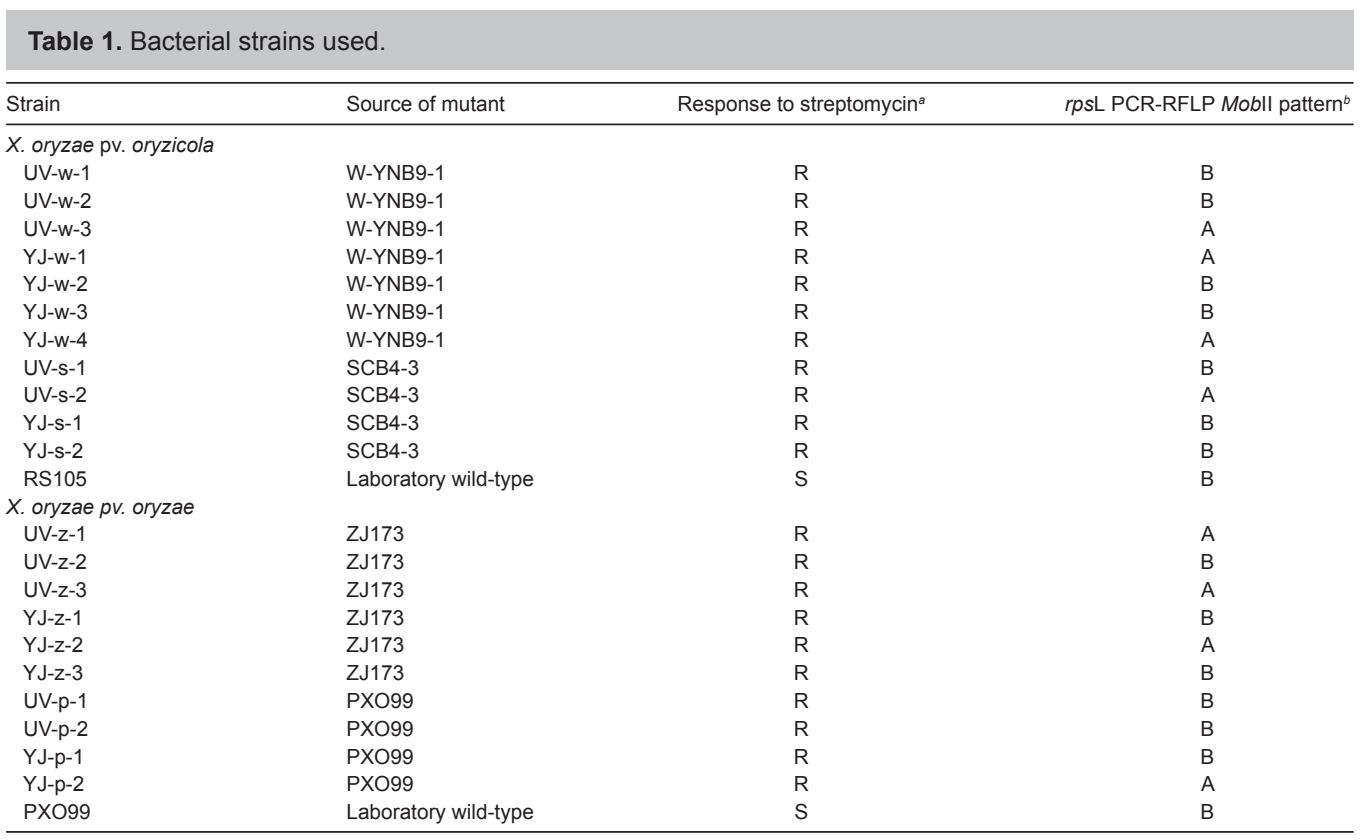

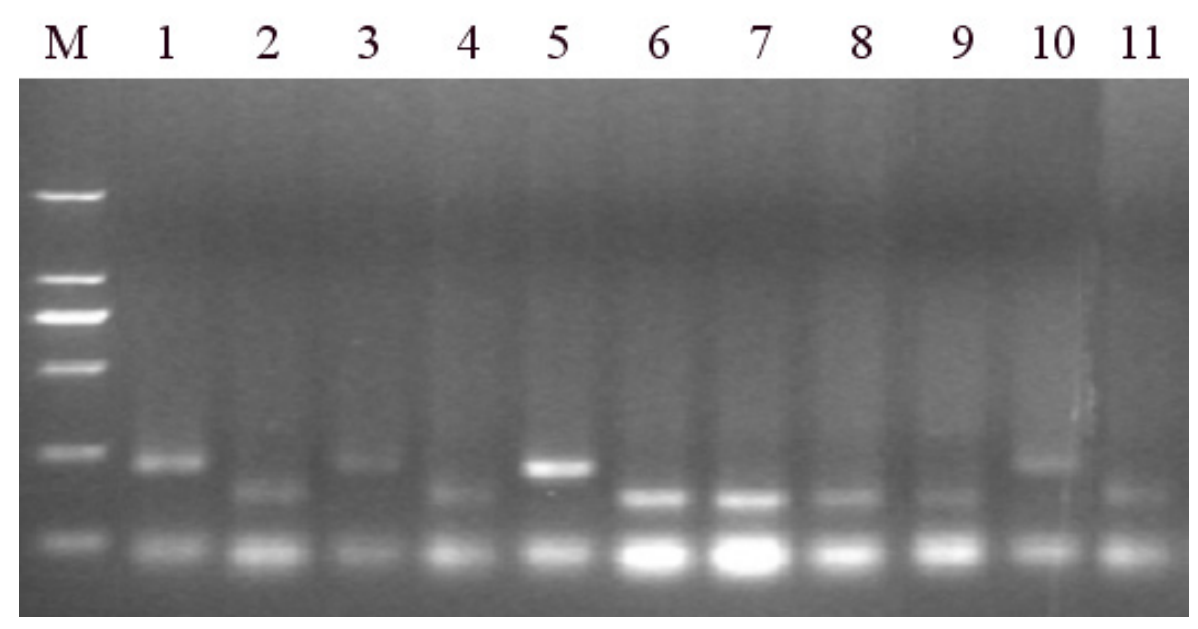

Figure 5. Detection of the mutation at codon 43 of the rpsL gene in $X$. oryzae pv. oryzae by RFLP analysis. The two patterns of digestion of the 304-bp amplified fragment of the rpsL gene by Mboll are shown. Lanes 1-11 = UV-Z-1, UV-z-2, UV-z-3, YJ-z-1, YJ-z-2, YJ-z-3, UV-p-1, UV-p-2, YJ-p-1, YJ-p-2, and PXO99, respectively; lane M = DL2000.

\section{DNA sequencing}

DNA sequence analysis showed that the rpsL amino acid sequences of $X$. oryzae pv. oryzicola and $X$. oryzae pv. oryzae were $97 \%$ identical. An open read fragment (ORF) of $375 \mathrm{bp}$ was obtained with the initiation codon ATG and the termination codon TGA, and the $(G+C)$ content 
was $61.36 \%$. All streptomycin-resistant strains had a single-point mutation in the rpsL gene. Out of the 21 streptomycin-resistant strains, eight were mutated at codon 43 and 13 were mutated at codon 88. AAG (Lys) at codon 43 or codon 88 was replaced by AGG (Arg), which resulted in the replacement of one amino acid $t$ (Figure 6). The distribution of rpsL mutations did not show a marked equilibrium between resistant mutants in that the mutation was more common at codon 88 than at codon 43, which was the same as previously reported for Mycobacterium tuberculosis (Dobner et al., 1997). The DNA sequencing data were completely consistent with the results of the RFLP analyses for these mutated strains.

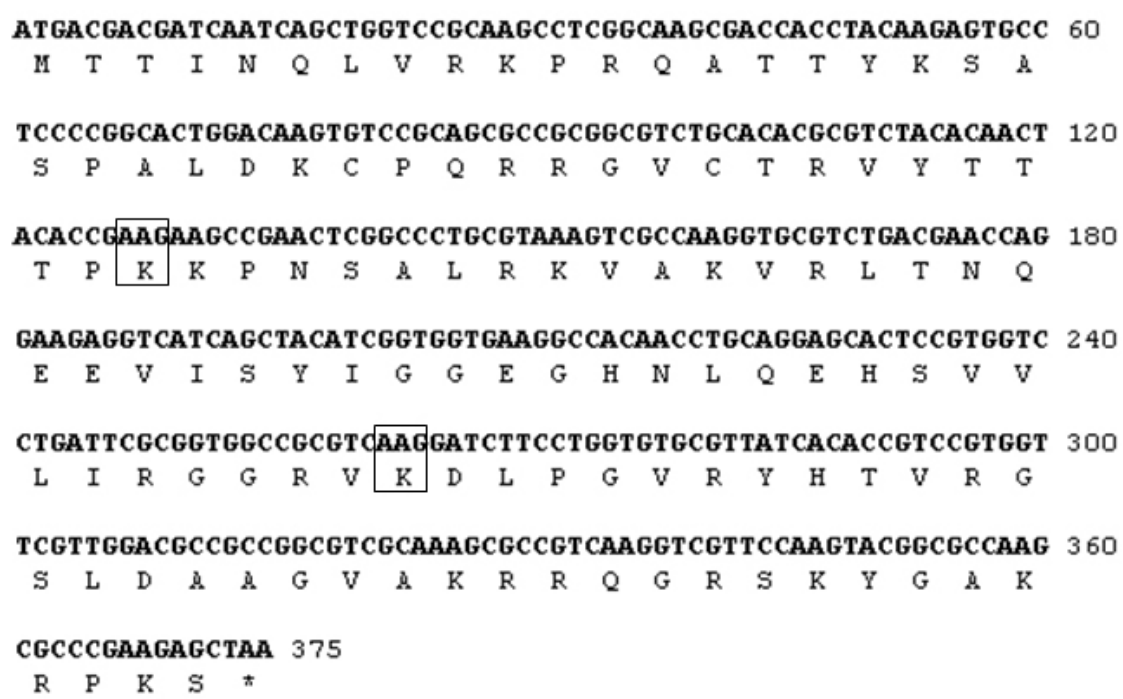

Figure 6. Nucleotide and deduced amino acid sequences of rpsL of $X$. oryzae pv. oryzicola and $X$. oryzae pv. oryzae showing Lys (AAG) mutated to Arg (AGG) at the 43rd or 88th amino acid residue. These two mutations could be involved in streptomycin-resistance in $X$. oryzae pv. oryzicola and $X$. oryzae pv. oryzae.

\section{DISCUSSION}

Streptomycin is an aminocyclitol glycoside antibiotic that is commonly used in the first-line treatment of tuberculosis. This antibiotic interferes with translational proofreading and thus inhibits protein synthesis. More specifically, streptomycin binds to the 305 ribosomal subunit, thereby interfering with polypeptide synthesis and inhibiting translation (Dobner et al., 1997). Chromosomally acquired resistance to streptomycin has frequently been shown to be due to mutation or other molecular changes in the genes encoding ribosomal protein S12 (rpsL) and 16S rRNA (rrs) (Wu et al., 2006). The strA-strB (Sundin et al., 2000, 2002) and aadA gene (Li et al., 2004; Poole et al, 2004; Weldhagen et al., 2004) can also confer streptomycin resistance.

In our previous research, the rpsL gene was cloned and ligated into the vector pUFR034. The plasmid containing the Lys $\rightarrow$ Arg mutation at the 43rd or 88th codon of the rpsL gene can confer streptomycin resistance to the sensitive wild-type strain by electroporation. This suggests that the streptomycin-resistance phenotype is caused by mutations in rpsL. Sequence comparison showed that a point mutation in this gene resulted in substitution of Arg by Lys at position 43 or 88 in streptomycin-resistant mutants. The same mutation was also reported in streptomycin-resistant 
strains of E. amylovora (Chiou et al., 1995), M. tuberculosis (Dobner et al., 1997), and Thermus thermophilus (Gregory et al., 2001). In the present study, the mutation frequency at codon 43 was $38.1 \%$ whereas that at codon 88 was $61.9 \%$. Conspicuously, the distribution of rpsL mutations did not show a marked equilibrium in resistant mutants in that the point mutation at codon 88 was more frequent than that at codon 43 , which is also true for genomic mutations in M. tuberculosis (Dobner et al., 1997).

The current study describes a new PCR-RFLP technique that can be used to detect streptomycin-resistant strains of $X$. oryzae pv. oryzicola and $X$. oryzae pv. oryzae. This method is less time-consuming than the conventional fungicide-susceptibility testing technique that is used to discriminate the mutation leading to streptomycin resistance. Although DNA sequencing is the most reliable method for determining the exact nature of the mutation, this method requires specialist equipment and techniques and is therefore unsuitable, or at least difficult, for routine use in the laboratory. The current study confirmed that the mutation at codon 43 of rpsL, which is associated with streptomycin resistance in $X$. oryzae pv. oryzicola and $X$. oryzae pv. oryzae could be rapidly identified by a simple, low-cost PCR-RFLP method (Katsukawa et al., 1997). This method, however, could not detect mutations at codon 88 of rpsL, and developing a PCR-RFLP method or other method to rapidly and easily detect mutations at this codon requires additional research.

\section{Conflicts of interest}

The authors declare they have no conflict of interest.

\section{ACKNOWLEDGMENTS}

This study was sponsored by the National Natural Science Foundation of China (\#31201550 and \#31272073), the Natural Science Foundation of Anhui Province (Grant \#1208085QC50), Special Fund for Agro-Scientific Research in the Public Interest from the Ministry of Agriculture, China (Grant \#201303015 and \#201303023), 2014 Science and Technological Fund of Anhui Province for Outstanding Youth (\#1408085J02), Special Fund for Quality Inspection Research in the Public Interest from the General Administration of Quality supervision, Inspection, and Quarantine of the People's Republic of China (\#201410076), Innovation Team of Anhui Academy of Agricultural Sciences (\#12C1105, \#13C1113, \#14C1111, and \#15C1105), Rice Industrial System of Anhui Province and the Dean Youth Innovation Fund of Anhui Academy of Agricultural Sciences (Grant \#13B1110).

\section{REFERENCES}

Al Dahouk S, Tomaso H, Prenger-Berninghoff E, Splettstoesser WD, et al. (2005). Identification of Brucella species and biotypes using polymerase chain reaction-restriction fragment length polymorphism (PCR-RFLP). Crit. Rev. Microbiol. 31: 191-196.

Chiou C and Jones A (1995). Molecular analysis of high-level streptomycin resistance in Erwinia amylovora. Phytopathology 85: 324-328.

Dobner P, Bretzel G, Rüsch-Gerdes S, Feldmann K, et al. (1997). Geographic variation of the predictive values of genomic mutations associated with streptomycin resistance in Mycobacterium tuberculosis. Mol. Cell Probes. 11: $123-126$.

Gregory ST, Cate JH and Dahlberg AE. (2001). Streptomycin resistant and streptomycin-dependent mutants of the extreme thermophile Thermus thermophilus. J. Mol. Biol. 309: 333-338.

Jeung JU, Heu SG, Shin MS, Vera Cruz CM, et al. (2006). Dynamics of Xanthomonas oryzae pv. oryzae populations in Korea 
and their relationship to known bacterial blight resistance genes. Phytopathology 96: 867-875.

Kang MJ, Shim JK, Cho MS, Seol YJ, et al. (2008). Specific detection of Xanthomonas oryzae pv. oryzicola in infected rice plant by use of PCR assay targeting a membrane fusion protein gene. J. Microbiol. Biotechnol. 18: 1492-1495.

Katsukawa C, Tamaru A, Miyata Y, Abe C, et al. (1997). Characterization of the rpsL and rrs genes of streptomycin-resistant clinical isolates of Mycobacterium tuberculosis in Japan. J. Appl. Microbiol. 83: 634-640.

Lai ZB, Shao M, Song CF, Chen GY, et al. (2004). Cloning of a dsp gene from Xanthomonas oryzae pv. oryzicola. J. Nanjing. Agric. Univ. 27: 41-45.

Li XZ and Nikaido H (2004). Efflux-mediated drug resistance in bacteria. Drugs 64: 159-204.

Nino-Liu DO, Ronald PC and Bogdanove AJ (2006). Xanthomonas oryzae pathovars: Model pathogens of a model crop. Mol. Plant Pathol. 7: 303-324.

Poole K (2004). Efflux-mediated multiresistance in gram-negative bacteria. Clin. Microbiol. Infect. 10: 12-26.

Salzberg SL, Sommer DD, Schatz MC, Phillippy AM, et al. (2008). Genome sequence and rapid evolution of the rice pathogen Xanthomonas oryzae pv. oryzae PXO99A. BMC Genomics 9: 204-219.

Strange RN and Scott PR (2005). Plant disease: A threat to global food security. Annu. Rev. Phytopathol. 43: 83-116.

Sundin GW (2000). Examination of base pair variants of the strA-strB streptomycin resistance genes from bacterial pathogens of humans, animals and plants. J. Antimicrob. Chemother. 46: 848-849.

Sundin GW (2002). Distinct recent lineages of the strA strB streptomycin-resistance genes in clinical and environmental bacteria. Curr. Microbiol. 45: 63-69.

Sundin GW and Bender CL (1993). Ecological and genetic analysis of copper and streptomycin resistance in Pseudomonas syringae pv. syringae. Appl. Environ. Microbiol. 59: 1018-1024.

Weldhagen GF (2004). Integrons and B-lactamases: A novel perspective on resistance. Int. J. Antimicrob. Agents 23: 556-562.

Wu XQ, Lu Y, Zhang JX, Liang JQ et al. (2006). Detection of streptomycin resistance in Mycobacterium tuberculosis clinical isolates using four molecular methods in China. Yi Chuan Xue Bao 33: 655-663.

Yong Z, Yu C, Xiaofeng Z, Ying X, Yiping H, Tongchun G and Mingguo Z (2011). A molecular mechanism of resistance to streptomycin in Xanthomonas oryzae pv. oyzicola. Phytoparasitica 39: 393-401. 